University of Nebraska - Lincoln

DigitalCommons@University of Nebraska - Lincoln

\title{
$9-2008$
}

\section{The Joint Role of Locus of Control and Perceived Financial Need in Job Search}

\author{
Edwin A. J. van Hooft \\ Institute of Psychology, Erasmus University Rotterdam, PO Box 1738, 3000 DR Rotterdam, The \\ Netherlands, vanhooft@fsw.eur.nl \\ Craig Crossley \\ University of Nebraska, Lincoln, ccrossley2@unl.edu
}

Follow this and additional works at: https://digitalcommons.unl.edu/managementfacpub

Part of the Management Sciences and Quantitative Methods Commons

van Hooft, Edwin A. J. and Crossley, Craig, "The Joint Role of Locus of Control and Perceived Financial Need in Job Search" (2008). Management Department Faculty Publications. 7.

https://digitalcommons.unl.edu/managementfacpub/7

This Article is brought to you for free and open access by the Management Department at DigitalCommons@University of Nebraska - Lincoln. It has been accepted for inclusion in Management Department Faculty Publications by an authorized administrator of DigitalCommons@University of Nebraska - Lincoln. 


\title{
The Joint Role of Locus of Control and Perceived Financial Need in Job Search
}

\author{
Edwin A. J. van Hooft ${ }^{a}$ and Craig D. Crossley ${ }^{b}$ \\ ${ }^{a}$ Institute of Psychology, Erasmus University Rotterdam, PO Box 1738, 3000 DR Rotterdam, The \\ Netherlands; vanhooft@fsw.eur.nl \\ ${ }^{b}$ Gallup Leadership Institute, University of Nebraska-Lincoln, Lincoln, NE 68588, USA
}

\begin{abstract}
Guided by economic rational choice theory and the behavioral-coping literature, the present study examined contrasting perspectives of the role of job-search locus of control (JSLOC) and perceived financial need in predicting job-search intensity. Data were collected in two independent studies in the Netherlands and in the United States, both using a two-wave longitudinal design. Results from both studies suggested that job seekers with external JSLOC and high perceived financial need engaged in more intense search behavior to compensate for anticipated difficulties in finding employment. Findings suggested that stress may mediate this relation, and may play a positive role in the job-search process.
\end{abstract}

\section{Introduction}

Job seekers' ability to find suitable employment has important implications for their subsequent careers and psychological well-being (McKee-Ryan, Song, Wanberg, \& Kinicki, 2005; Richards, 1984; Rosenbaum, 1979; Turner, 1995). The most important antecedent of finding employment is the intensity of one's job-search behavior, with more time and effort invested into job search being directly related to finding employment (Kanfer, Wanberg, \& Kantrowitz, 200I). These findings emphasize the importance of studying the jobsearch process and the predictors of job-search intensity.

In their meta-analysis, Kanfer et al. (200I) summarized the job-search literature by identifying five psychological complexes of job-search predictors: (a) Big Five personality traits, (b) self-evaluations (i.e., self-esteem and job-search self-efficacy), (c) motives (i.e., financial need and employment commitment), (d) perceptions of social support, and (e) locus of control/optimism expectancies. Whereas most complexes demonstrated meaningful relationships with job- search intensity, the results for locus of control/optimism expectancies were weak. Specifically, Kanfer et al. (200I) reported a statistically significant but negligible meta-analytic-based relation of.05 between locus of control and jobsearch intensity. The lack of meaningful findings for locus of control is peculiar given its long history in job-seeking research with a strong theoretical basis both in the behavioral coping (e.g., Leana \& Feldman, 1988; Wanberg, 1997) and the motivation literature (e.g., Feather \& O'Brien, 1987).

The current paper presents two studies designed to increase our understanding of the role of locus of control in the job-search process. Study I contrasts the behavioral coping approach with a compensatory approach based on the economic rational choice model (McFadyen \& Thomas, 1997). Furthermore, in order to explain the mixed and inconsistent findings of prior research on the relationship of locus of control with job-search intensity, Study I examines perceived financial need as an important moderating variable of this relation. Study 2 was designed to first examine the robustness of Study I findings across a different setting, and second to 
extend Study I by examining perceived stress as a mediating mechanism in the joint relationship of perceived financial need and job-search locus of control (JSLOC) with job-search intensity. As such the present paper contributes to the literature not only by advancing our understanding of the apparently complex role of locus of control in the job-search process but also by answering the call for research to take into account complex interrelations between individual predictors of job-search intensity (Vinokur \& Schul, 2002).

\section{Development of hypotheses}

\section{I. Behavioral coping approach}

Given the stressful nature of the job-search process, several researchers have posited that job-search behaviors are one way that job seekers cope with their anxieties (Barber, Daly, Giannantonio, \& Phillips, 1994; Wanberg, 1997). Research on behavioral coping has identified perceptions of control as important predictors of problem-focused coping strategies such as job seeking. Locus of control relates to one's subjective perception of the amount of control one has over outcomes of one's behavior. Whereas people with an internal locus of control perceive greater control over outcomes, those with an external locus of control attribute outcomes to external sources, such as powerful others, fate, or luck (Rotter, 1966).

In accordance with the behavioral coping approach, cognitive adaptation theory (Aspinwall \& Taylor, 1992; Taylor \& Brown, 1988) suggests that internal locus of control is related negatively to avoidant coping strategies and positively to problem-focused coping strategies. As applied to job seeking, cognitive adaptation theory suggests that an internal locus of control may stimulate unemployed individuals to engage in problem-focused coping strategies such as job seeking (Wanberg, 1997). Along these same lines, Leana and Feldman (1988) posited that unemployed individuals are more likely to engage in job search as an active coping strategy when they have an internal locus of control and regard their job loss as reversible. Furthermore, Wanberg, Glomb, Song, and Sorenson (2005) argued that locus of control is critical in coping with the stressful nature of job seeking, and should predict the persistence with which individuals engage in job search over time.

Notwithstanding these conceptual arguments, only weak cumulative evidence exists to suggest a relation between locus of control and job-search intensity. One possible explanation for the limited empirical support might be the generalized assessment of locus of control. Several researchers have therefore used a more contextually dependent assessment of control perceptions such as JSLOC, situational control, perceived control over job-search outcomes, and perceived reversibility of job loss. The essence of this highly related constellation of concepts seems to be captured by the construct JSLOC, which relates specifically to the amount of influence that job seekers believe to have over job-search outcomes (Saks \& Ashforth, 1999). Whereas an internal JSLOC refers to a person's belief that finding a job depends on one's own abilities, effort, and behaviors, external JSLOC refers to the belief that finding a job is determined solely by forces outside of oneself, such as luck, labor market conditions or decisions made by recruiters.' Consistent with previous research (e.g., Saks \& Ashforth, 1999; Wanberg, 1997), in the remainder of this paper we consider JSLOC as a continuous variable with high scores indicating an internal JSLOC and low scores indicating an external JSLOC.

Based on the behavioral coping perspective, a number of studies have empirically examined the relationship between JSLOC and job-search intensity. However, whereas Wanberg (1997) and Taris, Heesink, and Feij (1995) reported (modest) positive correlations between JSLOC and job-search intensity, other researchers have failed to find significant relationships (Feather \& O’Brien, 1987; Gowan, Riordan, \& Gatewood, 1999; Saks \& Ashforth, 1999; Van Hooft, Born, Taris, Van der Flier, \& Blonk, 2004b). Thus, whereas the coping approach suggests that people with an internal JSLOC should engage in more intense job-search behaviors than those with an external JSLOC, empirical support has been mixed. Nevertheless, based on conceptual arguments of coping theory and cognitive adaptation theory, the following hypothesis is forwarded, and further built upon with subsequent hypotheses.

Hypothesis I: Job-search locus of control is positively related to job-search intensity.

The inconsistency between theory and empirical findings on the JSLOC-job-search intensity relationship may suggest either (a) that the behavioral coping approach is not a suitable theoretical framework for explaining the JSLOCjob-search intensity relationship, or (b) that the JSLOC-jobsearch intensity relationship is positive for only a subset of job seekers. Based on these two explanations the next two sections first discuss the compensatory approach as an alternative theoretical framework to explain the JSLOC-jobsearch intensity relationship, and then introduce perceived financial need as possible moderator in the JSLOC-jobsearch intensity relationship. Both sections result in a competing hypothesis about the relationship between JSLOC and job-search intensity.

\subsection{Compensatory approach}

In contrast to the behavioral coping approach, several authors have articulated conceptual arguments suggesting that people with an external locus of control may compensate 
for their negative expectations by more proactively engaging in job-search activities. McFadyen and Thomas (1997), for example, questioned the presumed positive relationship between locus of control and job-search intensity by presenting qualitative evidence suggesting that individuals who have optimistic expectations of getting a job may actually invest little time in job seeking, instead delaying their search efforts. Saks and Ashforth (1999) also argued that individuals "with low perceptions of control may engage in a more active and intense job search as a compensatory response, trying to secure control where they in fact feel little" (p. 344). Furthermore they speculated that "job-seekers with high perceptions of control might conduct a more calculated and thoughtful search that is less active and intense" (pp. 344345). Taken together, these arguments on compensatory responses suggest a negative relationship between JSLOC and job-search intensity.

This compensatory approach can be further substantiated by the basic tenets of economic rational choice theory (see McFadyen \& Thomas, 1997) and control theory (Klein, 1989). The key argument of economic rational choice theory is that people behave in a rational and economic manner, and that individuals vary the level of effort invested in job search in accordance with the expected marginal returns. That is, people invest the minimal amount of effort and time in job seeking that is necessary to successfully attain a suitable job. Based on this logic, rational choice theory suggests that individuals with an internal JSLOC will be more optimistic that their own skills and abilities will result in them finding a job, and they will subsequently invest less time in job seeking compared with individuals who anticipate having little control over job-search outcomes. This rationale also aligns with control theory (Klein, 1989), which suggests that the discrepancy between one's actual state and one's goal state engenders negative emotions such as anxiety and stress, which can motivate the job seeker to compensate by working harder to achieve the goal. Applied to job seeking, individuals who attribute job-search outcomes to external forces may also perceive that more effort will be required to bridge the gap between their current un(der)employment and attainment of a suitable job.

In sum, whereas the behavioral coping approach predicts a positive relationship between JSLOC and job-search intensity, such that those who have an internal JSLOC are more likely to engage in job-search activities than those with an external JSLOC, the compensatory approach suggests a negative relationship, such that those who have an external JSLOC will compensate by engaging in more search behaviors. This leads to the following competing hypothesis:

Hypothesis 2: Job-search locus of control is negatively related to job-search intensity.
These conflicting theoretical perspectives suggest that the relation between JSLOC and job-search intensity may be more complex than originally thought. An interesting question relates to whether individual differences exist that may explain why people engage in a "coping response" or a "compensatory response." In the present study we focus on individual differences in perceived financial need as a moderator in the JSLOC-job-search intensity relationship. Findings from Vinokur and Schul (2002) suggested that perceived financial need may play a complex role in the job-search process, on one hand promoting success by motivating more intense search efforts, and on the other hand inhibiting successful search through decreasing job seekers' mental health and undermining their search efforts. Perceived financial need is next discussed in greater detail, followed by an explanation of how perceived financial need may moderate the JSLOC-job-search intensity relationship, resulting in a second competing hypothesis.

\subsection{Perceived financial need}

Perceived financial need is defined as job-seekers' subjective sense of how adequately their current income and monetary assets meet their personal and family needs ( $\mathrm{UI}$ lah, 1990). Perceived financial need can strongly affect people's psychological well-being (McKee-Ryan et al., 2005), and represents a psychological demand that exerts a motivational influence upon job seekers. In their seminal study, Barron and Gilley (1979) found that people with unemployment insurance spent significantly less time looking for a job than people without insurance. These authors concluded that unemployment insurance had a disincentive effect on search intensity. Turner (1995) suggested that financial need might further promote effortful job search by threatening job seekers' socioeconomic status and sense of self. Thus, given the psychological demands of financial need, people may be highly motivated to avoid if possible, or reconcile when necessary, further unemployment. Kanfer et al. (200I) reported a mean corrected correlation of.2I between financial need and job-search intensity, providing accumulated empirical evidence to support this notion.

\subsection{Joint effects of JSLOC and perceived financial need}

As noted before, a possible explanation for the inconsistency between theory and empirical findings on the relationship between JSLOC and job-search intensity may be that the JSLOC-job-search intensity relationship is positive for some job seekers and negative for others. In the present study, we propose perceived financial need as a moderating variable in the JSLOC-job-search intensity relationship that meaningfully distinguishes these groups of job seekers. 
More specifically, job seekers' perceived financial need may differentially affect the occurrence of compensatory responses among individuals with an internal vs external JSLOC. That is, situations of high perceived financial need are likely to evoke compensatory responses such that on the one hand individuals with an external JSLOC will feel a strong urge to compensate their low perceived control by investing much time and effort in job seeking. On the other hand, individuals with an internal JSLOC will feel less of an urge to engage in job seeking because they believe that attaining a job is within their control. However, in absence of strong external motivators such as a high perceived financial need, compensatory responses are less likely and JSLOC will have an intrinsically motivating effect for job seekers, such that individuals with an internal JSLOC will engage in more job seeking than those with an external JSLOC.

In other words, we expect the compensatory approach (i.e., JSLOC relates negatively to job-search intensity, such that internals search less intensely than externals) to be more valid in situations of high perceived financial need, and the behavioral coping approach (i.e., JSLOC relates positively to job-search intensity, such that internals search more intensely than externals) to be more valid in situations of low perceived financial need.

Hypothesis 3: Job-search locus of control and perceived financial need interact to predict search intensity, such that the relationship between JSLOC and job-search intensity is positive (negative) under conditions of low (high) perceived financial need.

\section{Current study}

Job search is an important behavior for individuals during several stages of their working lives. Previous research has mostly focused on job search among students searching for their first job upon graduation (e.g., Saks \& Ashforth, 1999, 2002), unemployed individuals looking for reemployment (e.g.,Vinokur \& Caplan, 1987; Wanberg, 1997; Wanberg et al., 2005) and employees looking for a new job (e.g., Blau, 1994; Boudreau, Boswell, Judge, \& Bretz, 200I). Although these streams of research have developed rather independently, several core concepts such as perceived financial need and JSLOC are relevant for all samples of job seekers (Kanfer et al., 200 I; Van Hooft et al., 2004b). In the current study we tested our hypotheses in two different samples of job seekers in two different countries.

Study I was conducted in the Netherlands and designed to test the role of JSLOC and perceived financial need in the prediction of job-search intensity in a sample of individuals via a large nation-wide temporary employment agency in the Netherlands. These individuals were working or had recently worked for one or more client organizations of the temp agency on a fixed-term or assignment basis that may vary between I day and several months. Job search is especially salient in this group because their employment position is relatively unstable and uncertain as compared with the position of permanent employees. However, even though there is an international trend in organizational staffing strategies towards hiring workers on a temporary basis (Connelly \& Gallagher, 2004), little research has paid attention to vocational behavior in such samples (see for an exception:Van Hooft, Born, Taris, \& Van der Flier, 2006). The study was conducted in the Netherlands, a country characterized by a relatively extensive social security system. Unemployed individuals are eligible for unemployment benefits and job-search assistance when registered at the public labor exchange and when they are capable and available for work. Unemployment benefits depend on the individual's working history and unemployment duration, being either $70 \%$ of their last salary (for individuals with a working history of at least 5 years and an unemployment duration of at most 5 years) or $70 \%$ of the statutory minimum wage (for individuals who are not eligible for the salary-related benefit). Individuals who cannot work because of sickness or disability mostly receive an income of $70 \%$ of their last salary (Social Security Administration, 2006a).

Study 2 was conducted in the United States and designed to test the robustness of Study I findings in a different sample of job seekers, that is, graduating college students. Study 2 further examined whether psychological stress plays a mediating role in the relationship between the JSLOC by perceived financial need interaction and job-search intensity. The social security system varies between the individual states in the United States. Most states have unemployment benefits of about $50 \%$ of the last earnings (with a maximum of about $50 \%$ of the states average wage) for the duration of 26 weeks. In most states unemployed individuals are eligible for receiving benefits only after having a certain amount of earnings in the period before unemployment (Social Security Administration, 2006b).

\section{Study I}

\section{I. Participants and procedure}

Time I questionnaires were sent by surface mail to a nation-wide random sample of 4985 temporary workers registered at a large employment agency in the Netherlands. 
In total 7/4 respondents returned the questionnaire. Time 2 data were collected 4 months later via structured telephone interviews in an effort to retain as many respondents in the sample as possible. In total 412 individuals completed the structured telephone interview. There were no monetary incentives for participating in the study. Respondents who completed both measurements were mailed a music $C D$ and a summary of the results. The data were collected as part of a larger study (Van Hooft, Born, Taris, \& Van der Flier, 2004a). Other than the zero-order correlations of job-search behavior with the demographic variables, no overlap exists between the original and the current study.

The characteristics of the 412 respondents in the final sample did not differ from the characteristics of the 714 respondents who participated at Time I only in terms of gender, age, level of education, employment position, perceived financial need, and JSLOC, $F(6,667)=1.23, p=.29$. As compared with the total random sample of 4985 individuals, the 412 respondents in the final sample were more often female, $M_{\text {final sample }}=.68$ vs $M_{\text {random sample }}=.50, t(481.78)=$ $7.39, p<.00 \mathrm{I}$, a little older, $M_{\text {final sample }}=28.16$ vs $M_{\text {random }}$ sample $=26.58, t(456.60)=2.62, p<.01$, and higher educated, $M_{\text {final sample }}=1.92$ vs $M_{\text {random sample }}=1.81, t(475.45)=3.65$, $p<.00 \mathrm{I}$.

Two-thirds of the 412 participants in the final sample were female $(n=279)$, and age ranged from 14 to $69(M=$ $28.16, S D=11.92)$. Level of education varied between primary school/lower vocational training (20.9\%), secondary school/high school/intermediate vocational training (63.3\%), and college/university (14.1\%), and $75.2 \%$ of the respondents were temporarily employed at Time I. Most participants were looking for jobs in commercial and financial services $(25.4 \%)$, hotel/catering $(19.3 \%)$, health care $(13.0 \%)$, sales (II.2\%), and transport (8.7\%). The majority preferred a permanent job $(60.7 \%)$, while $10.2 \%$ were looking for a temporary job. In total $42.2 \%$ were looking for a full-time job, whereas $39.4 \%$ preferred a part-time job. Examination of labor market conditions demonstrated that the unemployment rate was low in the Netherlands during the time of the study (i.e., $2.4 \%$ as compared with $7.7 \%$ in the European Union and $4.4 \%$ in the United States; Statistics Netherlands, 200I).

\subsection{Measures at Time I}

\subsection{Perceived financial need}

The individual's subjective financial situation was assessed with four items from Blau (1994) and Vinokur and Caplan (1987). Items were slightly adapted to make them suitable for both employed and unemployed job seekers (e.g., by replacing "salary" by "income," which refers not only to sal- ary but also to unemployment benefits, social security benefits, and welfare). The four items used were: "My current income allows me to maintain a desirable standard of living" (reverse coded), "I cannot afford much more than the basics on my current income,"“l have enough money to adequately support myself (and my dependents)" (reverse coded), and "It is difficult for me to live on my current income right now" (response options varied between I = strongly disagree to $5=$ strongly agree, $\alpha=.83$ ).

\subsubsection{JSLOC}

As described in Section 2, JSLOC can be defined as perceived control over job-search outcomes (Saks \& Ashforth, 1999), with an internal JSLOC referring to believing that finding a job depends on one's own effort, and an external JSLOC referring to believing that finding a job is determined solely by forces outside of oneself such as chance or luck. Consistent with this definition, JSLOC was assessed with five items based on measures by Vinokur and Caplan (1987), Feather and O'Brien (1987) and Wanberg (1997). Items were written to apply to both unemployed and temporarily employed job seekers. Participants answered questions such as "It is likely for me that I will get a (new) job if I try hard to find one," and "No matter how hard I try, chances are low that I will obtain (new) employment" (reverse coded) on a five-point scale (response options varied between I = strongly disagree to $5=$ strongly agree; $\alpha=.82$ ). High scores indicate an internal locus of control, whereas low scores indicate an external locus of control.

To examine the validity of our JSLOC measure, we administered it to a sample of 231 job seekers registered with a large Dutch reemployment-counseling firm, together with Saks and Ashforth's (1999) JSLOC measure (see Study 2) and Van Hooft et al.'s (2004b) job-search self-efficacy measure. Supporting the convergent validity, our JSLOC measure was highly correlated to Saks and Ashforth's (1999) JSLOC measure, $r=.60, p<.00 \mathrm{I}$. Supporting the divergent validity, the correlation with job-search self-efficacy was significantly lower, $r=.36, p<.00 \mathrm{I}, t(228)=3.78, p<.00 \mathrm{I}$.

\subsubsection{Control variables}

Gender, age, level of education, and employment status were included in the analyses as control variables, because previous research has shown that these variables are related to job-search intensity (Kanfer et al., 200I; Van Hooft et al., 2004b). Level of education was assessed by asking the respondents to indicate the highest level of education they completed. Employment status at Time I was assessed with the following item: "Do you have a paid job at the moment?" 
Table I. Study I means, standard deviations (SDs), and intercorrelations

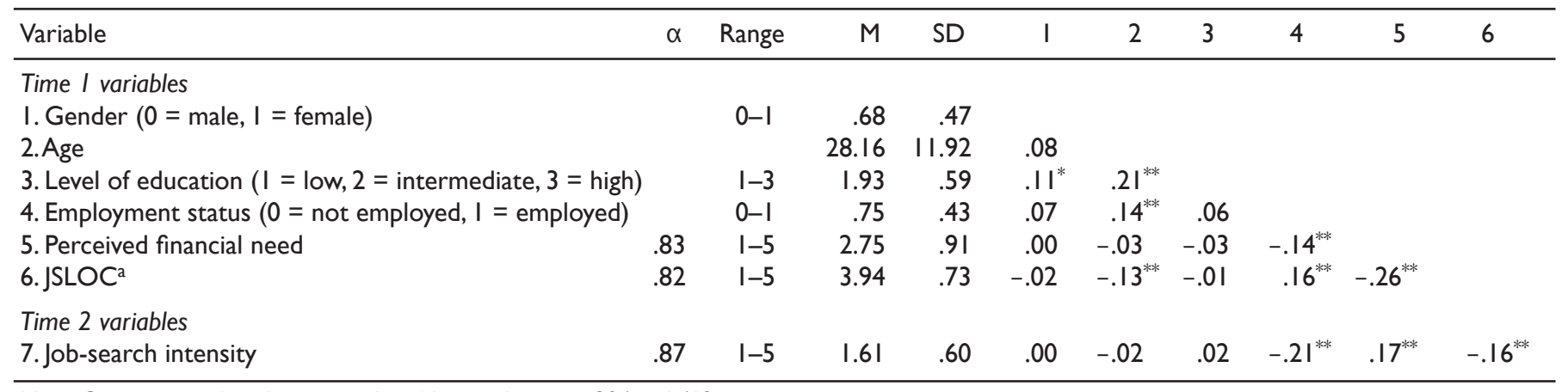

Note: Owing to incidental missing values $N$ varies between 394 and 412 .

a Job-search locus of control (JSLOC), with high (low) scores indicating an internal (external) locus of control.

${ }^{*} p<.05, \quad{ }^{*} p<.01$.

\subsection{Measures at Time 2}

Job-search intensity was assessed at Time 2 with II items based on Blau's (1994) behavioral scale. The items of Blau's scale were translated into Dutch and slightly adapted to the Dutch context and the specific characteristics of the sample (which contains both employed and unemployed job seekers, and a relatively large number of minimally educated job seekers). That is, one item was dropped because it applied to employed job seekers only ("Used current within company sources"). Another item was dropped because it concerned a highly uncommon job-search activity in the Netherlands ("Listed yourself as a job applicant in a newspaper"). Furthermore, two items were added to the scale, one about visiting job fairs, and one about the use of the internet to locate job openings (cf. Wanberg, Kanfer, \& Rotundo, 1999). The resulting scale included the following items: made inquiries/read about getting a job, prepared/revised resume, read classified/help wanted advertisements, talked with friends or relatives about possible job leads, spoke with previous employers or business acquaintances about possible job leads, visited job fairs, contacted employment agencies, looked for jobs on the internet, made inquiries to prospective employers, sent out application letters/filled out job applications, and gone on a job interview. Participants were asked to indicate how much time they had spent on these job-search activities in the last 4 months. Response options ranged from $\mathrm{I}=$ no time at all to $5=$ very much time, and $\alpha=.87$.

Previous research (see Kanfer et al., 200I) usually assessed job-search intensity with either an index measure based on Blau's (1994) behavioral scale like we did, or with a job-search effort measure or actual time spent on jobsearch measure. As a validity check for our job-search intensity index measure, we administered two additional items (Barber et al., 1994) asking for the amount of effort spent on job search and the number of hours per week devoted to job search. Reponses to both items were highly corre- lated with the scores on the job-search intensity index measure, $r=.8 \mathrm{I}, p<.00 \mathrm{I}$, and $r=.77, p<.00 \mathrm{I}$, respectively.

\section{Results and discussion}

Table I presents the means, standard deviations (SDs), and correlations among the Study I variables. Moderated multiple regression analysis of job-search intensity was used to test the hypotheses (see Table 2). Control variables were entered in the first step of the regression, followed by perceived financial need and JSLOC in the second step. Results showed a significant positive main effect of perceived financial need, $\beta=.12, p<.05$. Although the zero-order correlation between JSLOC and job-search intensity was significantly negative, JSLOC failed to explain unique variance after the demographics and perceived financial need were controlled for. The perceived financial need by JSLOC interaction was entered in the third step. The standardized interaction coefficient was significantly negative, $\beta=-.1 \mathrm{I}, p<$ .05. The form of the interaction was further analyzed following procedures recommended by Aiken and West (1991). As displayed in Figure I, JSLOC and perceived financial need interacted such that the JSLOC-job-search intensity relation was positive for individuals with a low perceived financial need and negative for individuals with a high perceived financial need. Analysis of the simple slopes in each group indicated that JSLOC was significantly and negatively related to job-search intensity for job seekers with high perceived financial need $(B=-.14, p<.01)$, but there was no relationship between these variables for job seekers with a low perceived financial need $(B=.03$, NS). The pattern of the interaction is largely consistent with Hypothesis 3, demonstrating that compensatory responses only occur in situations of high perceived financial need.

In summary, our results demonstrated that whereas perceived financial need was positively associated with job search, JSLOC played a more complicated role in the job- 
search context. That is, unlike the predictions of the behavioral coping approach (Hypothesis I) or the compensatory approach (Hypothesis 2), JSLOC did not have a main effect on job-search intensity. Instead, perceived financial need interacted with JSLOC to predict job-search intensity, such that the relationship was significantly negative under conditions of high perceived financial need, and positive (but not significant) under conditions of low perceived financial need. These results may help explain the contrasting findings of main effects of locus of control on job search reported in previous studies.

\section{Study 2}

As noted before, Study 2 presents a second test of the joint role of JSLOC and perceived financial need in predicting job-search intensity, using in a different sample (i.e., graduating students in the United States). In addition to the hypotheses presented in Study I, Study 2 examines whether stress may mediate the relationship of JSLOC and perceived financial need with job-search intensity.

Table 2. Study I moderated multiple regression analysis of jobsearch intensity on the predictors perceived financial need, job-search locus of control, and their interaction

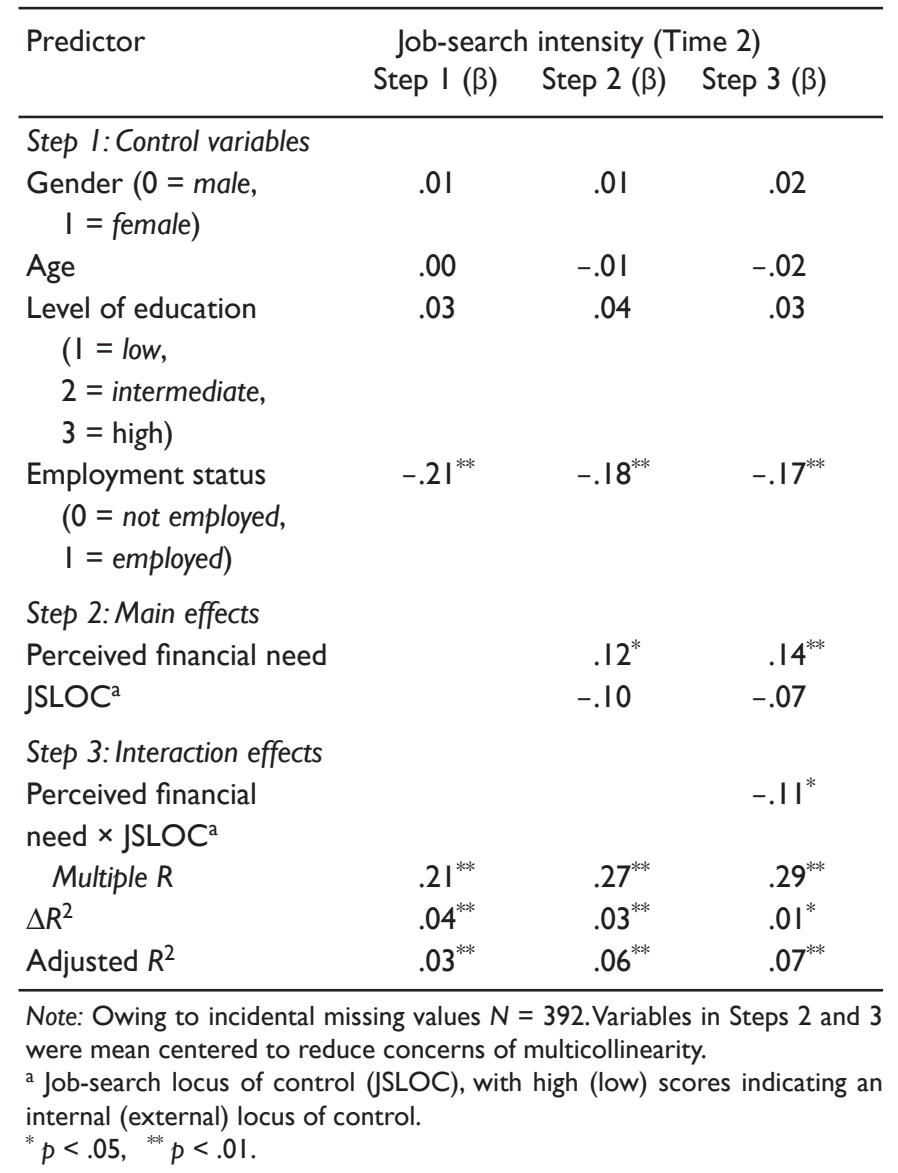

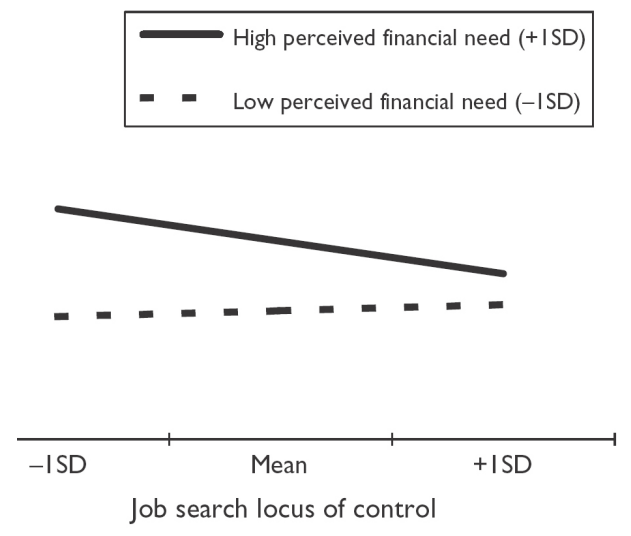

Figure I. Study I interaction between perceived financial need and job-search locus of control (JSLOC) in the prediction of job-search intensity. Note. Interaction plotted at one standard deviation above and below the mean for both perceived financial need and JSLOC.

\section{I.The mediating role of psychological stress}

Aside from the direct relation between perceived financial need and job-search intensity (Barron \& Gilley, 1979; Kanfer et al., 200I), previous research suggests that perceived financial need may relate to job-search intensity through increased stress. For instance, Vinokur and Schul (2002) suggested that at the same time perceived financial need promotes effortful search, it may hinder the job-search process through undermining job seekers' mental health. Although prolonged financial need may have a negative impact on selfesteem and self-efficacy, thereby interfering with search success (see Schaufeli \& Van Yperen, 1993), financial need may also have a more immediate and favorable effect of prompting earlier and more intense job-search behaviors through short-term perceived stress. In accordance with this notion, Wanberg (1997) suggested that increased time and energy spent on job search represent one form of control-oriented coping that job seekers may use to deal with financial demands. This implies that perceived financial need generates negative emotional states (e.g., anxiety and stress) with which people must cope. Control theory (Klein, 1989) further suggests that perceived stress associated with the gap between goal states (e.g., suitable employment) and actual states (e.g., un[der] employment) produces tension which may motivate behaviors aimed at reducing this gap.

In accordance with the compensatory approach, jobsearch intensity is expected to be greater among job seekers with a combined high perceived financial need and an external JSLOC. As these individuals may be more susceptible to experiencing stress, they may also be more likely to engage in job search as a way to minimize this negative psychological state. On the other hand, job seekers who believe that their search behaviors will dictate search out- 
comes may not worry as much about finding a job and may procrastinate their job-search efforts. Negative emotional states of stress and anxiety are posited to be the immediate outcomes of high perceived financial need (Wanberg, 1997) and low perceptions of control (Lazarus, 1998). In accordance with control theory, distress is further expected to antecede job-search behaviors (see also Barber et al., 1994; Wanberg, 1997). Thus, symptoms of stress are expected to mediate the joint relation between perceived financial need and JSLOC, and subsequent search intensity.

Hypothesis 4: Psychological stress will mediate the interaction of perceived financial need and JSLOC on subsequent job-search intensity.

\subsection{Participants and procedure}

In summarizing the job-seeking literature, Kanfer et al. (200I) identified three career stages during which job search is highly relevant: (a) during initial transitions into the work force, (b) after job loss, and (c) during job-to-job transitions. Corresponding to these stages, previous research on job seeking used samples of (a) workforce entrants such as graduating students, (b) unemployed individuals, or (c) employees. Whereas Study I used a mixed sample of employed and unemployed job seekers, Study 2 specifically focuses on graduating students. Job-search behavior is highly relevant among graduating students, not only because it prevents them from unemployment, but also because it affects the quality of their first job (Saks \& Ashforth, 2002) and their future careers (Richards, 1984; Rosenbaum, 1979). Furthermore, this sample of job seekers in the relatively early stages of job search also allowed an examination of the short-term effect of stress without the possible confound of a prolonged job search. Lastly, this sample was chosen to address criticisms that previous research has mostly used chronically unemployed persons to examine relations between well-being and job search (Feather, 1993), and has overlooked early stages of job search where failures such as procrastination may begin (see Kanfer \& Hulin, 1985).

Data for this study were collected in a two-wave longitudinal design as part of a larger study (Crossley \& Stanton, 2005). The only direct overlap in study measures were treated as control variables in the present study. A random sample of $\mathbf{8 8 4}$ graduating college students were contacted by email 2 months before graduation and asked to complete a web-based survey as part of a larger study. Two hundred and thirty-eight students who were entering the work force upon graduation (i.e., not continuing work with present employer, attending graduate school, internship, etc.), and who did not already have a job lined-up completed the first survey. This sample was $71 \%$ female, with an average age of 22 years $(S D=1.76)$. Respondents represented a variety of majors: $20 \%$ business, $15 \%$ education, $13 \%$ communications, II\% social science, $10 \%$ science $/$ math, $6 \%$ engineering/computer science, $6 \%$ performing arts, $6 \%$ health services, $13 \%$ other or not indicated. One hundred and forty-two $(60 \%$ response rate) of these participants completed the second survey approximately 6 weeks later. The timing of the surveys was discussed with employment counselors and was expected to span several weeks of active job search when graduation and perceived financial need were relatively salient. The characteristics of the respondents to the second survey were not statistically different from the characteristics of the population of graduating students in terms of age, $t=1.40$, or gender, $\square^{2}(1)=3.13$, or from the characteristics of the respondents to the first survey in terms of age, $t=.76$, or gender, $\square^{2}(I)=3.13$. An examination of labor market conditions suggested that the unemployment rate in the respective state $(3.9 \%)$ was slightly lower than the national average $(4.4 \%)$ during the time of the study (Bureau of Labor Statistics, 200 I).

\subsection{Measures}

Perceived financial need was assessed at Time I with Vinokur and Caplan's (1987) three-item measure of perceived financial need. Original items were reworded as follows to better represent the sample: "not having a job upon graduation would create actual hardships for me (and my family) such as inadequate housing, food, or medical attention,"'it would be difficult for me to live on my (total household) income if I have not located a job upon graduation,"' not having a job upon graduation would greatly reduce my standard of living to the bare necessities of life" (response options varied between I = strongly disagree to 5 $=$ strongly agree; $\alpha=.87$ ).

JSLOC was assessed at Time I with Saks and Ashforth's (1999) five-item scale. Job seekers responded to items such as "finding a job is totally within my control" on a five-point scale ( $I$ = strongly disagree to $5=$ strongly agree), with high scores reflecting internal JSLOC. The item "My ability to find a job is controlled by the labor market" (reverse scored) was removed based on a low item-total correlation $(r=$ .27). Removing this item increased the alpha reliability estimate from.64 to.69.

Perceived stress was measured with the seven-item stress scale from the Depression Anxiety Stress Scale (DASS, Lovibond \& Lovibond, 1995). This scale measures recently experienced symptoms of stress, and includes items such as "I find it difficult to relax" $(0=$ did not apply to me at all, to 3 = applied to me very much, or most of the time). Because we were interested in the relation of JSLOC and perceived financial need with the subsequent increase in stress 
symptoms, stress was measured at both Time I $(\alpha=.87)$ and Time $2(\alpha=.86)$, with Time I stress serving as a control variable.

Consistent with Study I, job-search intensity was assessed with Blau's (1994) preparatory and active job-search scale. The time frame of the questions was shortened to 6 weeks in order to better capture job-search activities in this sample occurring between Time I and Time 2 surveys $(\alpha=.83)$.

Because job-seekers' actual and perceived labor market value may have differed as a function of their age, sex, and/ or college major, these demographics were statistically controlled. College major was dummy coded using business majors as the reference group. Because trait negative affect has been posited as an underlying cause of correlations between stressors and strains (Chen \& Spector, 1991), participants' negative affective predisposition was statistically controlled with the 20-item Strain-Free Negative Affectivity Scale-Revised (SFNA-R; Fortunato \& Goldblatt, 2002). The SFNA$R$ includes items such as "If I were given a difficult project to work on, I would worry about it a lot." Responses were given on a scale from $\mathrm{I}=$ strongly disagree to $5=$ strongly agree $(\alpha=.90)$.

\section{Results and discussion}

Means, SDs, and intercorrelations for variables of interest appear in Table 3. Moderated regression analysis was used to test the hypotheses. Control variables were entered in the first step, followed by main effects for perceived financial need and JSLOC in step 2, and the interactive term in step 3. To test psychological stress as a mediator of the joint effect of perceived financial need and JSLOC on subsequent job-search intensity, stress was entered in step 4 . Results are summarized in Tables 4 and 5.
Consistent with findings from Study I, perceived financial need and JSLOC interacted to predict job-search intensity, $\beta=-.21, p<.05$ (see Table 5). As shown in Figure 2, and similar to Study I findings, JSLOC and perceived financial need interacted such that the relation between JSLOC and job-search intensity was positive for individuals with a low perceived financial need and negative for those with a high perceived financial need. An examination of simple slopes revealed that JSLOC was significantly and negatively related to job-search intensity for job seekers with high perceived financial need $(B=-.20, p<.01)$, but there was no relationship between these variables for job seekers with a low perceived financial need $(B=.08$, NS). This finding is largely consistent with Hypothesis 3 and findings from Study I, and offers additional evidence that compensatory responses may only occur in situations of high perceived financial need.

Hypothesis 4 suggested that perceived financial need and JSLOC interact to predict job-search intensity through their association with perceived stress. This hypothesis was tested using Baron and Kenny's (1986) test of mediated moderation. According to Baron and Kenny (1986), support for mediation is indicated if the following conditions are met: (I) the independent variable (in this case the interaction of JSLOC and perceived financial need) significantly predicts the dependent variable; (2) the independent variable significantly predicts the mediator (see Table 4), (3) the mediator significantly predicts the dependent variable, and (4) the effect of the independent variable on the dependent variable is weaker or non-significant when the mediator is included as a predictor. In partial support of Hypothesis 4 , when stress was entered in the model $(\beta=.18, p<.05)$, the interactive term between perceived financial need and JSLOC reduced in magnitude but remained statistically significant, offering some evidence of partial mediation. A one-tail Sobel test of mediation suggested the indirect effect was significant in the expected direction $(Z=-1.67, p<.05)$.

Table 3. Study 2 means, standard deviations (SDs), and intercorrelations

\begin{tabular}{|c|c|c|c|c|c|c|c|c|c|c|c|c|}
\hline Variable & $\alpha$ & Range & M & SD & 1 & 2 & 3 & 4 & 5 & 6 & 7 & 8 \\
\hline \multicolumn{2}{|c|}{ I. Gender $(0=$ male, I = female $)$} & $0-1$ & .74 & .44 & & & & & & & & \\
\hline 3. Negative affectivity & .90 & $1-5$ & 3.11 & .68 & .08 & -.07 & & & & & & \\
\hline 4. Stress & .87 & $0-3$ & 1.27 & .56 & .14 & .00 & $.52^{* *}$ & & & & & \\
\hline 5. Job-search intensity & .82 & $\mathrm{I}-5$ & 1.93 & .59 & .04 & -.03 & .09 & .05 & & & & \\
\hline \multicolumn{13}{|l|}{ Time 2 variables } \\
\hline 8. Stress & .86 & $0-3$ & 1.73 & .56 & .09 & -.07 & $.48^{* *}$ & $.67^{* *}$ & .05 & $.17^{*}$ & -.03 & \\
\hline 9. Job-search intensity & .83 & $\mathrm{I}-5$ & 1.96 & .59 & .07 & .03 & .10 & .02 & $.61^{* *}$ & .11 & -.13 & .20 \\
\hline
\end{tabular}




\section{General discussion}

The present study more closely examined the relation between JSLOC and perceived financial need and subsequent job-search intensity using two two-wave longitudinal studies. The classic behavioral coping approach of the role of JSLOC was contrasted with a compensatory approach, based on conceptual arguments of McFadyen and Thomas (1997), Saks and Ashforth (1999), and further substantiated by the basic tenets of economic rational choice theory (see McFadyen \& Thomas, 1997) and control theory (Klein, 1989). Findings from both studies suggest that perceived financial need moderates the influence of JSLOC on the effort that individuals invest in job seeking. Specifically, job seekers with an external JSLOC were found to display more job-search activity than those with an internal JSLOC when perceived financial need was high. In contrast, when perceived financial need was low, the relationship between JSLOC and jobsearch intensity was slightly (but not significantly) positive. As such, these findings demonstrate support for the compensatory approach of the role of JSLOC in situations when perceived financial need is high. Support for the behavioral coping approach, which was expected to be more valid in situations of low perceived financial need, was weak.

Table 4. Study 2 moderated multiple regression analysis with perceived financial need and locus of control as predictors of stress

\begin{tabular}{|c|c|c|c|}
\hline Predictor & $\begin{array}{l}\text { Stress } \\
\text { Step I ( } \beta)\end{array}$ & Step 2 ( $\beta)$ & Step $3(\beta)$ \\
\hline \multicolumn{4}{|l|}{ Step I: Control variables } \\
\hline $\begin{array}{l}\text { Gender }(0=\text { male, } \\
\quad I=\text { female })\end{array}$ & -.05 & -.05 & -.07 \\
\hline Age & -.04 & -.04 & -.05 \\
\hline Negative Affectivity & .14 & $.16^{*}$ & $.15^{*}$ \\
\hline Stress (Time I) & $.60^{* *}$ & $.65^{* *}$ & $.63^{* *}$ \\
\hline \multicolumn{4}{|l|}{ Step 2: Main effects } \\
\hline Perceived financial need & & .12 & .11 \\
\hline JSLOCa & & -.12 & -.11 \\
\hline \multicolumn{4}{|l|}{ Step 3: Interaction effects } \\
\hline $\begin{array}{l}\text { Perceived financial } \\
\text { need } \times \text { JSLOC }{ }^{a}\end{array}$ & & & $-.13^{*}$ \\
\hline Multiple $R$ & $.69^{* *}$ & $.17^{* *}$ & $.72^{* *}$ \\
\hline$\Delta R^{2}$ & $.48^{* *}$ & $.03^{*}$ & $.02^{*}$ \\
\hline Adjusted $R^{2}$ & $.42^{* *}$ & $.44^{* *}$ & $.46^{* *}$ \\
\hline \multicolumn{4}{|c|}{$\begin{array}{l}\text { Note: Owing to incidental missing values } N=142 \text {. College majors (dummy } \\
\text { coded) were included in the statistical models, but were not significantly } \\
\text { related to stress or search intensity. Because of space concerns college } \\
\text { majors are not included in this table. Variables in Steps } 2 \text { and } 3 \text { were mean } \\
\text { centered to reduce concerns of multicollinearity. } \\
\text { a Job-search locus of control (JSLOC), with high (low) scores indicating an } \\
\text { internal (external) locus of control. } \\
* p<.05, \quad p<.01 \text {. }\end{array}$} \\
\hline
\end{tabular}

\section{I.Theoretical implications}

These results contribute to research on the job-search process in several ways. First, this study found empirical evidence of the important role of JSLOC in explaining search intensity. Though the role of this variable in the job-search process has been identified by other scholars (Saks \& Ashforth, 1999; Vinokur, Price, \& Schul, 1995; Wanberg, 1997), their empirical findings have been mixed (see Kanfer et al., 200I). The present study demonstrates that the presence of moderators in the JSLOC-job-search intensity relationship (specifically perceived financial need) may explain previous mixed findings. Our findings were largely consistent across two different samples of job seekers (i.e., temporary workers and graduating students), in two different countries with different socioeconomic and employment systems (i.e., the Netherlands and the United States), and using slight variations in methods and measures. This suggests that our findings represent a fairly robust and generalizable process whereby perceived financial need and JSLOC relate to subsequent job-search intensity.

Further, using a mediated-moderator model, this study found some evidence to suggest that perceived stress may be an underlying mechanism whereby the interaction between JSLOC and perceived financial need relates to jobsearch intensity. These findings may challenge traditional perspectives (Hamilton, Hoffman, Broman, \& Rauma, 1993; Schaufeli \& Van Yperen, 1993) and practice (see Vinokur \& Schul, 2002) that suggests that stress is a nuisance to the job-search process and should be completely eliminated. Indeed, findings from the present study suggest that, at least in the short term, stress may actually be related to more active job search, especially among job seekers with an external JSLOC and high perceived financial need. These findings suggest that as a proximal variable it may be perceived stress, rather than perceived financial need (Vinokur \& Schul, 2002), that plays a dual role in the search process; on one hand inciting search behavior, and on the other hand challenging job seekers' self-esteem and self-efficacy when search is prolonged. It is both theoretically and practically important to distinguish between these variables in models of job search, as efforts to manage stress can be quite different than efforts aimed at reducing perceived financial need.

\subsection{Practical implications}

Findings from the present study may inform practice and extend research on intervention studies, suggesting that over and above any direct relation with job-search intensity, JSLOC may interact with other variables such as per- 
Table 5. Study 2 moderated multiple regression analysis with perceived financial need and locus of control as predictors of job-search intensity

\begin{tabular}{|c|c|c|c|c|}
\hline \multirow[t]{2}{*}{ Predictor } & \multicolumn{4}{|c|}{ Job-search intensity (Time 2) } \\
\hline & Step I ( $\beta)$ & Step $2(\beta)$ & Step $3(\beta)$ & Step $4(\beta)$ \\
\hline \multicolumn{5}{|l|}{ Step I: Control variables } \\
\hline Age & .10 & .11 & .10 & .11 \\
\hline Negative affectivity & .10 & .08 & .07 & .05 \\
\hline \multicolumn{5}{|l|}{ Step 2: Main effects } \\
\hline Perceived financial need & & .01 & .02 & .04 \\
\hline JSLOC ${ }^{a}$ & & -.10 & -.11 & $-.14^{*}$ \\
\hline \multicolumn{5}{|l|}{ Step 3: Interaction effects } \\
\hline$\Delta \mathrm{R}^{2}$ & $.48^{* *}$ & .01 & $.04^{* *}$ & $.02^{*}$ \\
\hline Adjusted $\mathrm{R}^{2}$ & $.42^{* *}$ & $.42^{* *}$ & $.46^{* *}$ & $.47^{* *}$ \\
\hline
\end{tabular}

Note: Owing to incidental missing values $N=$ 137. College majors (dummy coded) were included in the statistical models, but were not significantly related to distress or search intensity. Because of space concerns college majors are not included in this table.Variables in Steps 2 and 3 were mean centered to reduce concerns of multicollinearity.

a Job-search locus of control (JSLOC), with high (low) scores indicating an internal (external) locus of control.

${ }^{*} p<.05,{ }^{* *} p<.01$.

ceived financial need to influence job-search processes and outcomes. These findings may be useful to student career advisors, vocational rehabilitation counselors, or welfareto-work agencies wishing to prompt earlier or more active search, and to identify individuals who may most benefit from career counseling. These findings may also be useful to recruiters in identifying active periods of anxiety driven search, which may be informative to the timing and content of job ads and internet recruitment strategies (Cober, Brown, Keeping, \& Levy, 2004).

Furthermore, the findings suggest that stress may play a role in prompting early search and in reducing unrealistically high expectations. By reducing one's expectations and career goals, a job seeker may give organizations a more favorable position in negotiating wages and job assignments. Thus, recognizing and properly dealing with stress experienced during job search may help job seekers determine and maintain realistic employment goals and self-regulated search activities necessary to attain suitable employment.

Regarding job-search intervention training, although it does not, in itself, reduce job-seekers' actual financial need, it may be useful in reducing the impact of perceived financial need on job seekers' psychological well-being by enhancing their sense of self-mastery (Vinokur et al., 1995; Vinokur \& Schul, 2002; Vuori \& Vesalainen, 1999). In addition, the present findings suggest that short-term stress may serve as a catalyst to activate job search, and therefore should not be completely eliminated. As this finding contrasts previous research which has suggested negative effects of stress on jobsearch outcomes (at least in conditions of long-term unemployment), further research is necessary to determine the conditions where stress may be beneficial before practical implications can be unequivocally recommended.

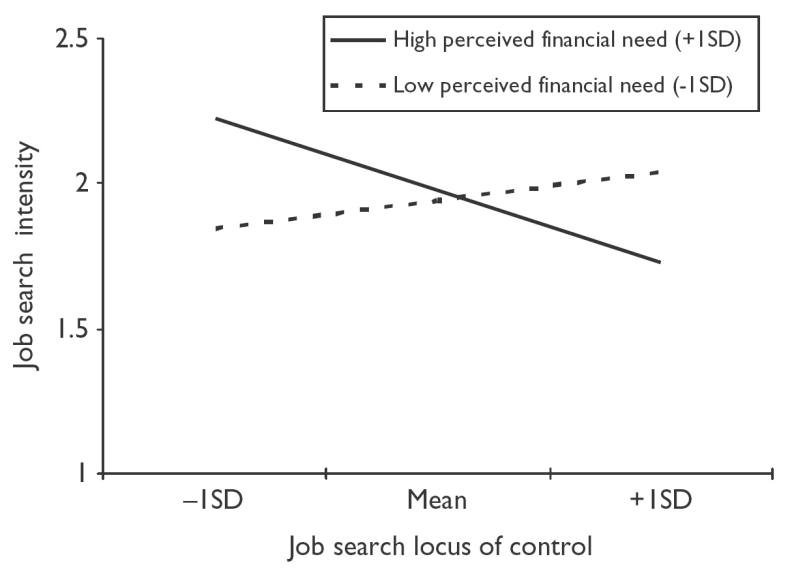

Figure 2. Study 2 interaction between perceived financial need and job-search locus of control (JSLOC) in the prediction of job-search intensity. Note. Interaction plotted at one standard deviation above and below the mean for both perceived financial need and JSLOC. 


\subsection{Limitations and future research}

Several limitations of the present study warrant caution in the interpretation of results. A first limitation is that participants provided all of the data on the study variables, leading to concerns of common method and self-report biases. Although these concerns may be somewhat reduced by temporally separating predictors from criteria and controlling for plausible third variables, such as trait negative affect, future research should seek to obtain peer ratings and the use of more objective measures of financial need, control over search outcomes, and search behaviors.

Furthermore, the low response rate in the Study I sample might limit the generalizability of the findings. It should be noted in this context that the population from which this sample was drawn included a large proportion of lower educated individuals and low response rates are not uncommon in such situations (e.g., Schmit, Amel, \& Ryan, 1993; Van Hooft et al., 2004b). Comparison of the respondents with the non-respondents revealed that the sample was slightly biased in terms of gender, age, and educational level, potentially limiting generalizability.

Third, although the data in both studies were collected in a longitudinal design, it included only two points in time. As both job-search behavior as well as attitudes and cognitions about job seeking may change overtime (Barber et al., 1994; Wanberg et al., 2005), future research should include more measurement points in time to capture the dynamic role of JSLOC, perceived financial need, and perceived stress in explaining job-search intensity.

A fourth possible limitation relates to the fact that the data of Study I and Study 2 were collected in different countries with different labor market conditions and social security systems. On the one hand, this may suggest robustness of our findings in different contexts. On the other hand, this may limit the comparability of our findings. However, unemployment rates in both studies were comparably low (i.e., $2.4 \%$ and $3.9 \%$ ). Furthermore, despite the differences in social security systems, in both countries unemployment results in a significant reduction of income and in increased financial need.

A fifth limitation relates to the types of job-seeker populations that were investigated: temporary workers and graduating students. Although job search is a highly relevant and salient behavior in these samples, the mean levels of jobsearch activity were rather low. It should be noted, however, that job-search intensity was measured using an index of II or 12 different search activities. Individuals engaging in a targeted job search may concentrate on two or three jobsearch activities, which results in a relatively low mean score on the multiple-item index. Furthermore, the job seekers examined in the present study are less likely to engage in job seeking at a full-time basis because they are temporarily employed or are still in school. In addition, the average age of the samples in the present study was relatively low (i.e., 28.2 in Study I and 22.3 in Study 2). Older job seekers may have different experiences and pressures that may influence their job search. Therefore, future research should investigate the interaction of JSLOC with financial need and the mediating role of stress in predicting job-search intensity in other samples (e.g., unemployed job seekers, older job seekers).

Given its long history in job-seeking research with a strong theoretical basis both in the behavioral coping (e.g., Leana \& Feldman, 1988; Wanberg, 1997) and the motivation literature (e.g., Feather \& O'Brien, 1987), previous findings on the role of locus of control in predicting job-search intensity were disappointing (e.g., Kanfer et al., 200I). The present study, however, demonstrated that perceived financial need moderates the JSLOC-job-search relationship. Future research should investigate whether other variables may affect the role of JSLOC in predicting search intensity (e.g., human capital). More generally, future research should pay more attention to interdependent relations between predictors of job search (cf.Vinokur \& Schul, 2002).

While beyond the scope of the present study, one important implication worthy of future research is that time may moderate the potential dual role of stress on jobsearch success, such that stress has a short-term positive impact on job-search success through increased search behavior, but a negative long-term impact through undermining job-seekers' sense of well-being. Future research may also examine how stress affects job-search goals and strategies (see Crossley \& Highhouse, 2005), perceptions of treatment during the selection process (Derous, Born, \& De Witte, 2004), and how job-search cycles may be integrated into staffing cycles (Carlson \& Connerley, 2003). Along these lines, research may explore connections between stress experienced during job search and subsequent underemployment (Feldman, 1996).

Finally, the hypothesized linear relationship between stress and job-search intensity research may be a too simple representation of the underlying mechanisms. The effects of stress on job-search intensity may not be linear, and be advantageous by motivating action only up to some point, whereas too much stress may inhibit search behaviors. Although we tested for, but did not detect non-linear effects in this study, future research is needed to further examine possible non-linear effects of stress.

\subsection{Conclusion}

In conclusion, the present study found that JSLOC and perceived financial need interact such that job seekers with high 
perceived financial need and external JSLOC experience more stress and engage in more intense job search to compensate for anticipated difficulties in finding a job, whereas people with an internal JSLOC may procrastinate search efforts. As such, these findings demonstrate support for the compensatory approach rather than the behavioral coping approach of the role of JSLOC. Future research is needed to further investigate the generalizability of these findings in samples of older, unemployed, and employed job seekers, and to further examine the dual role of stress in the jobsearch process.

\section{Note}

I. Job-search locus of control (JSLOC) should be distinguished from job-search self-efficacy, another important construct in the jobsearch literature. Whereas JSLOC involves the perceived control that job seekers believe to have over the outcomes of their job search (Saks \& Ashforth, 1999; see also Wanberg, 1997), jobsearch self-efficacy involves the perceived control that job seekers believe to have over the job-search behaviors. That is, jobsearch self-efficacy is typically defined as one's confidence in performing tasks that are important in the job-search process (Saks \& Ashforth, 1999), or as perceptions of mastery over jobsearch behaviors (Kanfer \& Hulin, 1985).

\section{References}

Aiken, L.S. and West, S.G. (199I) Multiple regression:Testing and interpreting interactions. Newbury Park, CA: Sage.

Aspinwall, L.G. and Taylor, S.E. ( 1992) Modeling Cognitive Adaptation: A longitudinal investigation of the impact of individual differences and coping on college adjustment and performance. Journal of Personality and Social Psychology, 63, 989-1003.

Barber, A.E., Daly, C.L., Giannantonio, C.M. and Phillips, J.M. (I994) Job Search Activities: An examination of changes over time. Personnel Psychology, 47, 739-766.

Baron, R.M. and Kenny, D.A. (1986) The Moderator-Mediator Variable Distinction in Social Psychological Research: Conceptual, strategic, and statistical considerations. Journal of Personality and Social Psychology, 5 I, I I73-I 182.

Barron, J.M. and Gilley, O.W. (1979) The Effect of Unemployment Insurance on the Search Process. Industrial and Labor Relations Review, 32, 363-366.

Blau, G. (1994) Testing a Two-Dimensional Measure of Job-Search Behavior. Organizational Behavior and Human Decision Processes, 59, 288-3I2.

Boudreau, J.W., Boswell,W.R., Judge, T.A. and Bretz, R.D. (200I) Personality and Cognitive Ability as Predictors of Job Search Among Employed Managers. Personnel Psychology, 54, 25-50.

Bureau of Labor Statistics. (200I). Unemployment rate-local area unemployment statistics. Retrieved February 14, 2004 from http:// stats.bls.gov .
Carlson, K.D. and Connerley, M.L. (2003) The Staffing Cycles Framework:Viewing staffing as a system of decision events. Journal of Management, 29, 5I-78.

Chen, P.Y. and Spector, P.E. (I99I) Negative Affectivity as the Underlying Cause of Correlations Between Stressors \& Strains. Journal of Applied Psychology, 76, 398-407.

Cober, R.T., Brown, D.J., Keeping, L.M. and Levy, P.E. (2004) Recruitment On the Net: How do organizational web site characteristics influence applicant attraction? Journal of Management, 30, 623-646.

Connelly, C.E. and Gallagher, D.G. (2004) Emerging Trends in Contingent Work Research. Journal of Management, 30, 959-983.

Crossley, C.D. and Highhouse, S. (2005) Relation of Job Search and Choice Process with Subsequent Satisfaction. Journal of Economic Psychology, 26, 810-819.

Crossley, C.D. and Stanton, J.M. (2005) Negative Affect and Job Search: Further examination of the reverse causation hypothesis. Journal of Vocational Behavior, 66, 549-560.

Derous, E., Born, M.Ph. and De Witte, K. (2004) How Applicants Want and Expect to be Treated:Applicants' selection treatment beliefs and the development of the social process questionnaire on selection. International Journal of Selection and Assessment, I 2 , 99-119.

Feather, N.T. (1993) Success and Failure in the Labor Market: Some comments. Journal of Organizational Behavior, I4, 573-576.

Feather, N.T. and O'Brien, G.E. (1987) Looking for Employment: An expectancy-valence analysis of job-seeking behaviour among young people. British Journal of Psychology, 78, 25I-272.

Feldman, D.C. (1996) The Nature, Antecedents and Consequences of Underemployment. Journal of Management, 22, 385-407.

Fortunato,V.J. and Goldblatt, A.M. (2002) Construct Validation of Revised Strain-Free-Negative Affectivity Scale. Educational and Psychological Measurement, 62, 45-63.

Gowan, M.A., Riordan, C.M. and Gatewood, R.D. (1999) Test of a Model of Coping with Involuntary Job Loss Following a Company Closing. Journal of Applied Psychology, 84, 75-86.

Hamilton, V.L., Hoffman, W.S., Broman, C.L. and Rauma, D. (I 993) Unemployment, Distress, and Coping: A panel study of autoworkers. Journal of Personality and Social Psychology, 65, 234-247.

Kanfer, R. and Hulin, C.L. (1985) Individual Differences in Successful Job Searches Following Lay-Off. Personnel Psychology, 38, 835-847.

Kanfer, R.,Wanberg, C.R. and Kantrowitz,T.M. (200I) Job Search and Employment: A personality-motivational analysis and meta-analytic review. Journal of Applied Psychology, 86, 837-855.

Klein, H.J. ( 1989 ) An Integrated Control Theory Model of Work Motivation. Academy of Management Review, I4, I50-I72.

Lazarus, R.S. (1998) Fifty Years of the Research and Theory of R. S. Lazarus:An analysis of historical and perennial issues. Mahwah, NJ: Lawrence Erlbaum Associates.

Leana, C.R. and Feldman, D.C. (1988) Individual Responses to Job Loss: Perceptions, reaction, and coping behaviors. Journal of Management, 14, 375-389.

Lovibond, P.F. and Lovibond, S.H. (1995) The Structure of Negative Emotional States: Comparison of the depression anxiety stress 
scales (DASS) with the Beck depression and anxiety inventories. Behaviour Research and Therapy, 33, 335-343.

McFadyen, R.G. and Thomas, J.P. (1997) Economic and Psychological Models of Job Search Behavior of the Unemployed. Human Relations, 50, |46I-| 484 .

McKee-Ryan, F.M., Song, Z., Wanberg, C.R. and Kinicki, A.J. (2005) Psychological and Physical Well-Being During Unemployment:A meta-analytic study. Journal of Applied Psychology, 90, 53-76.

Richards, E.W. (1984) Early Employment Situations and Work Role Satisfaction Among Recent College Graduates. Journal of Vocational Behavior, 24, 305-318.

Rosenbaum, J.E. (1979) Tournament Mobility: Career patterns in a corporation. Administrative Science Quarterly, 24, 220-24I.

Rotter, J.B. (1966) Generalized Expectancies for Internal Versus External Control of Reinforcement. Psychological Monographs, 80, I-26.

Saks, A.M. and Ashforth, B.E. (1999) Effects of Individual Differences and Job Search Behaviors on the Employment Status of Recent University Graduates. Journal of Vocational Behavior, 54, 335-349.

Saks, A.M. and Ashforth, B.E. (2002) Is Job Search Related to Employment Quality? It All Depends on Fit. Journal of Applied Psychology, 87, 646-654.

Schaufeli, W.B. and Van Yperen, N.W. (1993) Success and Failure in the Labour Market. Journal of Organizational Behavior, I4, 559-572.

Schmit, M.J., Amel, E.L. and Ryan, A.M. (1993) Self-Reported Assertive Job-Seeking Behaviors of Minimally Educated Job Hunters. Personnel Psychology, 46, I05-124.

Social Security Administration. (2006a) Social Security Programs Throughout the World: Europe, 2006. Washington, DC: Social Security Administration.

Social Security Administration. (2006b) Social security programs throughout the world:The Americas, 2005. Washington, DC: Social Security Administration.

Statistics Netherlands. (200I) Het Jaar in Cijfers 200I [The Year in Numbers 200I]. Voorburg/Heerlen, the Netherlands: Statistics Netherlands.

Taris, T.W., Heesink, J.A.M. and Feij, J.A. (1995) The Evaluation of Unemployment and Job-Searching Behavior: A longitudinal study. Journal of Psychology, I29, 30I-3I4.

Taylor, S.E. and Brown, J.D. (1988) Illusion and Well-Being: A social psychological perspective on mental health. Psychological Bulletin, 103, 193-210.
Turner, J.B. (1995) Economic Context and Health Effects of Unemployment. Journal of Health and Social Behavior, 36, 213-229.

Ullah, P. (1990) The Association Between Income, Financial Strain and Psychological Well-Being Among Unemployed Youth. Journal of Occupational Psychology, 63, 317-330.

Van Hooft, E.A.J., Born, M.Ph., Taris, T.W. and Van der Flier, H. (2004a) Job Search and the Theory of Planned Behavior: Minority-majority group differences in The Netherlands. Journal of Vocational Behavior, 65, 366-390.

Van Hooft, E.A.J., Born, M.Ph., Taris, T.W. and Van der Flier, H. (2006) Ethnic and Gender Differences in Applicants' Decision-Making Processes: An application of the theory of reasoned action. International Journal of Selection and Assessment, 14, I56-166.

Van Hooft, E.A.J., Born, M.Ph., Taris, T.W., Van der Flier, H. and Blonk, R.W.B. (2004b) Predictors of Job Search Behavior Among Employed and Unemployed People. Personnel Psychology, 57, 25-59.

Vinokur, A.D. and Caplan, R.D. (1987) Attitudes and Social Support: Determinants of job-seeking behavior and well-being among the unemployed. Journal of Applied Social Psychology, I7, I007-I 024.

Vinokur, A.D., Price, R.H. and Schul,Y. (1995) Impact of the JOBS Intervention on Unemployed Workers Varying in Risk for Depression. American Journal of Community Psychology, 23, 39-74.

Vinokur, A.D. and Schul,Y. (2002) The Web of Coping Resources and Pathways to Reemployment Following a Job Loss. Journal of Occupational Health Psychology, 7, 68-83.

Vuori, J. and Vesalainen, J. (1999) Labour Market Interventions as Predictors of Re-Employment, Job Seeking Activity and Psychological Distress Among the Unemployed. Journal of Occupational and Organizational Psychology, 72, 523-538.

Wanberg, C.R. (1997) Antecedents and Outcomes of Coping Behaviors Among Unemployed and Reemployed Individuals. Journal of Applied Psychology, 82, 73I-744.

Wanberg, C.R., Glomb, T.M., Song, Z. and Sorenson, S. (2005) JobSearch Persistence During Unemployment: A I0-wave longitudinal study. Journal of Applied Psychology, 90, 4I I-430.

Wanberg, C.R., Kanfer, R. and Rotundo, M. (1999) Unemployed Individuals: Motives, job-search competencies, and job-search constraints as predictors of job-seeking and reemployment. Journal of Applied Psychology, 84, 897-910. 